\title{
P158: Posting a management dashboard improves behaviour in the $\mathrm{OR}$
}

\author{
R Meinke ${ }^{*}$, OT Reuthebuch ${ }^{2}$, J Fassl ${ }^{3}$, I Gisler ${ }^{3}$, M Heiberger $^{3}$, M Seeberger $^{3}$, FS Eckstein ${ }^{2}$, AF Widmer ${ }^{1}$ \\ From 2nd International Conference on Prevention and Infection Control (ICPIC 2013) \\ Geneva, Switzerland. 25-28 June 2013
}

\section{Introduction}

Surgical site infections (SSIs) lead to increased morbidity and mortality. Guidelines to prevent SSIs have been issued, but adherence is commonly low. Interventions in the OR to improve adherence are frequently short term. A dashboard is a management tool used in industries showing defined performance indicators at a glance, it is easily accessible to everyone and recipients are able to influence the indicators. We tested this approach in cardiac surgery with defined process parameters that were regularly monitored.

\section{Methods}

In interdisciplinary team-meetings, all process indicators were discussed, and a well-defined set approved, all being recommended by WHO. The dashboard was posted monthly at the OR entry, and reported to the cardiac-thoracic-surgery-team in 2-monthly meetings. The survey period lasted from 10/2011-11/2012.

\section{Parameters and aims}

- Timing of Antibiotic-prophylaxis (30-60 min before incision)

- Preoperative temperature (core temperature $>36^{\circ} \mathrm{C}$ prior incision)

- Discipline in the OR (hand-disinfection performed at 5 moments WHO; no jewellery/or covered; correct wearing of surgical mask)

The indicators were surveyed by $\sim 4$ control-visits in the OR per month as well as by analysis of data from the electronic OR chart. The feedback of adherence was simplified by using a traffic-light-system that was implemented to show parameters at a glance and posted monthly at the OR-doors:

${ }^{1}$ Infectious Diseases and Hospital Epidemiology, University Hospital Basel, Basel, Switzerland

Full list of author information is available at the end of the article

\section{Colour-system}

- RED (not fulfilled; Score 0 points)

- ORANGE (limited adherence; score 1 point)

- GREEN (fulfilled; score 2 points)

Maximal achievable points are 16.

\section{Results}

Analysis of parameters showed an increase in compliance over time, from an average of 7 points at start of the survey-period to an average of $15(\mathrm{p}<0.05)$. However, two time periods showed decreased adherence, but rapidly exceeded the level of previous months.

\section{Conclusion}

The very simple dashboard provided rapid and easy feedback on compliance to guidelines. It was readily accepted by members of the interdisciplinary team, and helped to improve the teams' performance. If supported by senior staff and open discussion of not fulfilled parameters this tool helps to sustain high levels of adherence after an initial intervention.

\section{Disclosure of interest}

None declared.

\section{Author details}

'Infectious Diseases and Hospital Epidemiology, University Hospital Basel, Basel, Switzerland. ${ }^{2}$ Cardiac Surgery, University Hospital Basel, Basel,

Switzerland. ${ }^{3}$ Anaesthesiology, University Hospital Basel, Basel, Switzerland.

Published: 20 June 2013

doi:10.1186/2047-2994-2-S1-P158

Cite this article as: Meinke et al: P158: Posting a management

dashboard improves behaviour in the OR. Antimicrobial Resistance and Infection Control 2013 2(Suppl 1):P158.

\section{C)

( 2013 Meinke et al; licensee BioMed Central Ltd. This is an Open Access article distributed under the terms of the Creative Commons Attribution License (http://creativecommons.org/licenses/by/2.0), which permits unrestricted use, distribution, and reproduction in any medium, provided the original work is properly cited. 